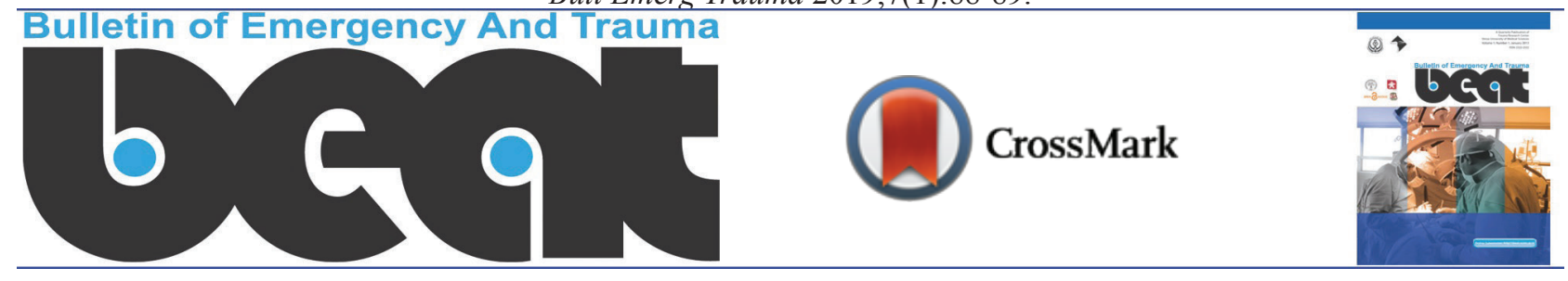

\title{
Rhino-orbital Mucormycosis
}

\author{
Satvinder Singh Bakshi ${ }^{1 *}$
}

${ }^{1}$ Mahatma Gandhi Medical College and Research Institute, Sri Balaji Vidyapeeth, India

*Corresponding author: Satvinder Singh Bakshi

Address: Mahatma Gandhi Medical College and Research Institute, Sri Balaji Vidyapeeth, India.

e-mail: saty.bakshi@gmail.com
Received: September 11, 2018

Revised: September 25, 2018

Accepted: September 28, 2018

Please cite this paper as:

Bakshi SS. Rhino-orbital Mucormycosis. Bull Emerg Trauma. 2019;7(1):88-89. doi: 10.29252/beat-0701015.

A 52-year-old male with type I diabetes since 16 years and chronic kidney disease since 10 years presented with pain and swelling of his right eye since 5 days associated with loss of vision since 3 days. On examination there was a blackish eschar in the right nasal cavity. Ophthalmologic examination revealed chemosis, proptosis and complete ophthalmoplegia of the right eye along with complete loss of vision (Figure 1A). The patient underwent surgical debridement and orbital exenteration and was started on amphotericin $\mathrm{B}$; however, his deteriorated and ultimately he succumbed to the illness 2 days later. The biopsy from the lesion was consistent with mucormycosis (Figure 1B).

About $70 \%$ of rhinocerebral cases are found in diabetic patients in ketoacidosis, others at risk are patients with solid organ or hematopoietic stem cell transplantation $[1,2]$. The initial symptoms are of eye or facial pain and facial numbness. If untreated, infection spreads to the orbit, resulting in ptosis,

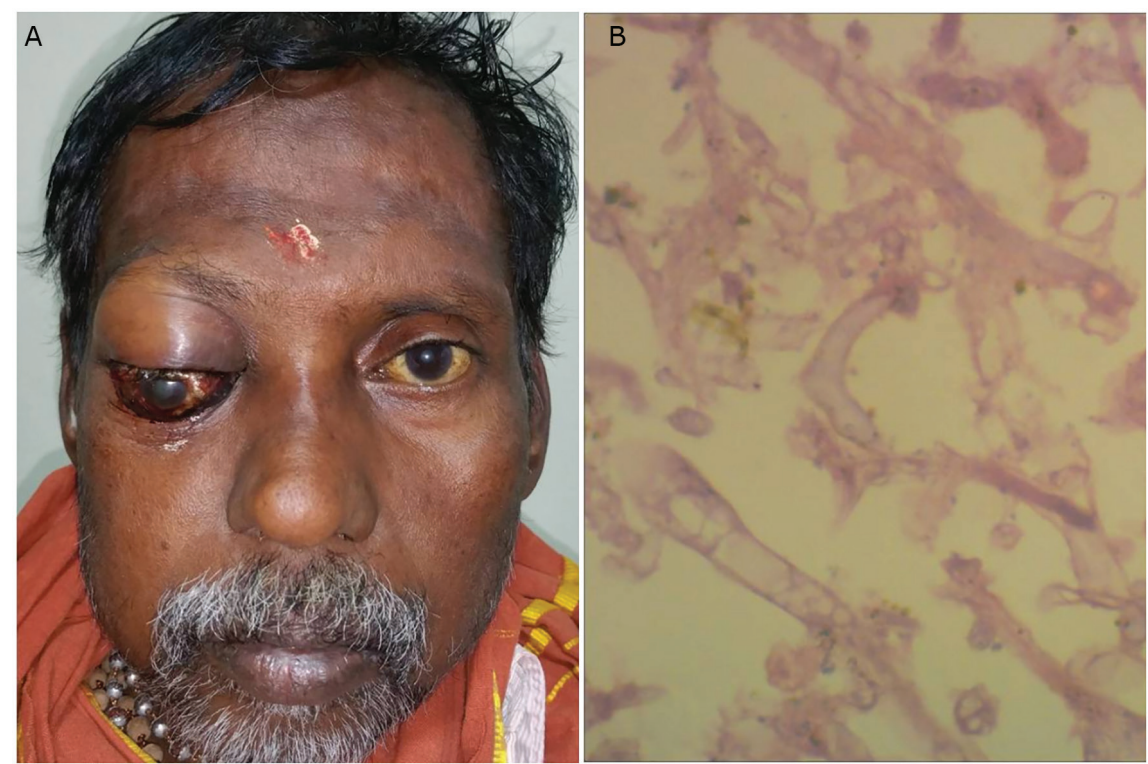

Fig. 1. Patient with right eye proptosis and ptosis (A); Section show fungal organisms with broad angle branching hyphae suggestive of mucormycosis $(\mathrm{HE}, \times 400)(\mathbf{B})$. 
chemosis, and proptosis $[2,3]$. Involvement of the cavernous sinus leads to cranial nerve III, IV, V, VI palsies and permanent blindness [3]. Diagnosing mucormycosis requires histopathological evidence of fungal invasion of the tissues and the extent of involvement can be assessed with CT or MRI scans [2]. The treatment is based on early identification, reversal of underlying pathology, surgical debridement of the infected tissue and starting antifungal therapy with amphotericin B [1-3]. The prognosis varies between 30 to $70 \%$ and worsens with the involvement of cavernous sinus [3].

Conflicts of Interest: None declared.

\section{References}

1. Jeong W, Keighley C, Wolfe R, Lee WL, Slavin MA, Kong DCM, et al. The epidemiology and clinical manifestations of mucormycosis: a systematic review and meta-analysis of case reports. Clin Microbiol Infect. 2018.
2. Sarvestani A, Pishdad G, Bolandparvaz S. Predisposing Factors for Mucormycosis in Patients with Diabetes Mellitus; An Experience of 21 Years in Southern Iran. Bull Emerg Trauma. 2013;1(4):164-70

3. Sarvestani A, Pishdad G, Bolandparvaz
S. Epidemiology and Clinical Characteristics of Mucormycosis in Patients with Leukemia; A 21-year Experience from Southern Iran. Bull Emerg Trauma. 2014;2(1):38-43.

\section{Open Access License}

All articles published by Bulletin of Emergency And Trauma are fully open access: immediately freely available to read, download and share. Bulletin of Emergency And Trauma articles are published under a Creative Commons license. Mandated authors will be offered CC-BY; all other authors will choose between CC-BY, CC-BY-NC and CC-BY-NC-ND. 